\title{
Relationships among Event-Related Potentials, Memory, and Schizophrenic Symptoms in College Students with Schizotypal-Traits
}

\author{
Kyoung-Mi Jang, Myung-Sun Kim*
}

Sungshin Women's University, Seoul, Korea

Email: ${ }^{*}$ kimms@sungshin.ac.kr

Received 5 July 2014; revised 9 August 2014; accepted 12 September 2014

Copyright (C) 2014 by authors and Scientific Research Publishing Inc.

This work is licensed under the Creative Commons Attribution International License (CC BY). http://creativecommons.org/licenses/by/4.0/

(c) (7) Open Access

\begin{abstract}
The present study investigated the relationships among event-related potentials (ERPs), memory, and schizophrenic symptoms in college students with schizotypal-traits. Scores on the Schizotypal Personality Questionnaire (SPQ) were used to categorize the participants into schizotypal-trait (n $=30)$ and normal control $(n=37)$ groups. ERPs were assessed using an auditory oddball paradigm, in which a series of standard tones $(1000 \mathrm{~Hz})$ and target tones $(1500 \mathrm{~Hz})$ were presented; participants were asked to count the number of presented target tones. The verbal memory and visual memory of the participants were evaluated using the Korean version of the California Verbal Learning Test (K-CVLT) and the Rey-Osterrieth Complex Figure Test (RCFT), respectively. The schizotypal-trait and control groups did not differ in terms of age, educational level, IQ score, accuracy on the auditory oddball task, or performance on the K-CVLT and RCFT measures. However, the schizotypal-trait group exhibited significantly smaller P300 amplitudes than the control group. Additionally, the P300 amplitudes measured at $\mathrm{Cz}$ and Pz were negatively correlated with the cognitive-perceptual factor scores on the SPQ. Thus, the present results indicate that reduced P300 amplitudes may represent a biological marker of schizophrenia.
\end{abstract}

\section{Keywords}

Schizotypal-Trait, Event-Related Potentials, P300, Auditory Oddball Paradigm, Cognitive-Perceptual Factor of the SPQ

\footnotetext{
${ }^{*}$ Corresponding author.
}

How to cite this paper: Jang, K.-M. and Kim, M.-S. (2014) Relationships among Event-Related Potentials, Memory, and Schizophrenic Symptoms in College Students with Schizotypal-Traits. Open Journal of Psychiatry, 4, 353-363. 


\section{Introduction}

Event-related potentials (ERPs) are widely used to investigate the neurophysiological mechanisms underlying various cognitive functions. ERPs are composed of positive and negative peaks and represent electrical activities that are time-locked to events [1]. Due to the excellent temporal resolution inherent in this technique, ERPs have been effectively used to study cognitive functions that are comprised of series of processes [2].

Although a variety of experimental designs using ERPs have been used, the oddball paradigm is among those most frequently employed. This paradigm involves the presentation of series of standard and target stimuli and the participant is required to attend to the target stimuli, which are rarely presented, amid the standard stimuli, which are presented frequently. ERP studies using the oddball paradigm consistently find that compared to standard stimuli target stimuli elicit larger amplitudes of the P300 component, which is a positive peak observed approximately 250 - 450 ms after stimulus-onset [3] [4]. P300 is known to reflect memory updating [3] or the allocation of attentional resources [5].

Since Sutton, Braren, Zubin and John [4] reported that P300 could be used as an index of information processing, a number of studies have attempted to understand the cognitive characteristics of patients with schizophrenia using this ERP component [6]-[9]. For example, P300 amplitude is consistently attenuated in patients with schizophrenia compared to normal controls [10]-[12] and reductions in P300 amplitude have been observed in first-episode patients [13] [14] and the healthy family members of patients [15]. These findings suggest that reduced P300 amplitudes are independent of the chronicity of the illness and antipsychotic medications and could serve as a biological marker of schizophrenia [6].

However, the clinical implications of reduced P300 amplitudes in patients with schizophrenia remain poorly understood [16] [17]. An examination of the relationship between P300 abnormalities and neuropsychological performance may contribute to a better understanding of the clinical significance associated with reduced P300 amplitudes. Patients with schizophrenia exhibit significant negative associations between P300 amplitudes and performance on the verbal paired-association [16] and visual memory [17] tests of the Wechsler Memory Scale. Additionally, P300 amplitudes and verbal memory performance on the Luria-Nebraska Verbal Learning Test are negatively correlated [12].

A few studies have investigated the relationship between P300 abnormalities and schizophrenic symptoms, and have yielded relatively inconsistent results. P300 amplitudes and the negative symptoms of schizophrenia, including social withdrawal and blunted affect, are negatively correlated [18] [19], but negative associations have also been observed between P300 amplitudes and the positive symptoms of schizophrenia, such as hallucinations and delusions [20] [21].

Abnormalities in other ERP peaks, such as N100 and N250, are also present in patients with schizophrenia. The amplitudes of the N100 [22] and N250 [23] peaks, which index selective attention and the classification/ categorization of stimuli, respectively, exhibit reductions in patients with schizophrenia.

Schizophrenia is a severe mental disorder that often takes a chronic course, and the progress of the patient deteriorates the longer the symptoms remain untreated. Therefore, the identification and treatment of schizophrenic patients in the early stages of the disease are of great importance [24]. Furthermore, recently there has been increased interest in identification of individuals who are at a high-risk for schizophrenia because patients with schizophrenia tend to experience disorder-related symptoms and cognitive difficulties prior to being diagnosed [25]. Traditionally, the healthy family members of a schizophrenic patient have been regarded as having a highgenetic risk for schizophrenia but recent investigations of patients with schizotypal personality disorder (SPD) and non-clinical individuals with schizotypal-traits have attempted to reveal the biological markers of schizophrenia [23] [26]-[28]. Indeed, SPD and schizophrenia share common abnormal genetic [29], neuroimaging [30], and neuropsychological [31] [32] markers. Additionally, reduced P300 amplitudes are observed in patients with SPD [33] and college students with schizotypal-traits [34] [35].

Thus, the present study investigated whether college students with psychometrically defined schizotypal-traits exhibit ERP abnormalities, particularly reduced P300 amplitudes. Furthermore, if P300 amplitudes were reduced, the relationships of this abnormality with memory function and schizophrenic symptoms were assessed. The findings of the present study further characterize the nature of P300 amplitudes and determine whether they can serve as a biological marker of schizo-spectrum disorders, including schizophrenia. 


\section{Methods}

\subsection{Participants}

The present study included 67 college students who were recruited from a pool of 800 students based on scores on the Korean version of the Schizotypal Personality Questionnaire (SPQ, [36]). Students in the top of 5\% of the SPQ scores were included in the schizotypal-trait group $(\mathrm{n}=30 ; 14$ males and 16 females) while the control group ( $\mathrm{n}=37$; 18 males and 19 females) was comprised of students with average scores ( $\pm 1 \mathrm{SD}$ ) on the SPQ [31] [36]. The Structured Clinical Interview for DSM-IV, non-patient version (SCID-NP, [37]) was administered to ensure that the participants did not have a history of psychiatric, medical or neurological disorders or drug/alcohol abuse. All patients were right-handed and none were taking medication at the time of testing. The participants were paid for their participation, and provided written informed consent after receiving a complete description of the study. The study was approved by the Sungshin Women's University Institutional Bioethics Review Board.

\subsection{Electrophysiological Recording and the Auditory Oddball Task}

Electroencephalographic (EEG) activity was recorded using a Net Amp 300 amplifier (Electrical Geodesics, Eugene, OR, USA) and an auditory oddball paradigm in an electrically shielded and sound-proofed experimental room. A total of 200 stimuli were presented during the oddball task: 160 standard stimuli $(1000 \mathrm{~Hz}, 80-\mathrm{dB}$ sound pressure level [SPL]) and 40 target stimuli $(1500 \mathrm{~Hz}, 80-\mathrm{dB}$ SPL). All stimuli were presented for a duration of $40 \mathrm{~ms}$ with $10 \mathrm{~ms}$ rise/fall times, and with an inter-stimulus interval of $1500 \mathrm{~ms}$. Participants were required to count the number of target stimuli presented, and report this at the end of the experiment.

A total of 64 sites were recorded using a 64-channel HydroCel Geodesic Sensor net (Electrical Geodesics, Eugene, OR, USA) with all electrodes referenced to $\mathrm{Cz}$, and adjusted until the impedance was less than $50 \mathrm{k} \Omega$ [38]. Eye movements and blinks were monitored by electrodes placed beneath and near the outer canthus of the left eye. EEG activity was continuously recorded throughout the experiment using a 0.1 - $100 \mathrm{~Hz}$ analog bandpass with a sampling rate of $250 \mathrm{~Hz}$. Following data collection, the EEG data were segmented into $1000 \mathrm{~ms}$ epochs (including a $100 \mathrm{~ms}$ pre-stimulus baseline). Epochs contaminated by artifacts such as eye blinks and eye movements were rejected prior to the averaging (the threshold for artifact rejection was \pm peak-to-peak amplitude of $70 \mu \mathrm{V}$ ). All data associated with the standard and target stimuli were averaged separately with an average-reference transformation and the ERPs were digitally low-pass filtered at $30 \mathrm{~Hz}$. The EEG data associated with correct responses were subjected to statistical analysis.

Mean correct responses on the oddball task were $39.49(\mathrm{SD}=1.07)$ and $39.13(\mathrm{SD}=1.89)$ for the schizotypal-trait and control groups, respectively. The mean number of trials included in the final statistical analysis for the schizotypal-trait and control groups were $22.53(\mathrm{SD}=8.01)$ and $23.78(\mathrm{SD}=7.94)$, respectively. The two groups did not differ in terms of accuracy $(\mathrm{t}(65)=0.96$, ns) or the number of trials included in the analysis $(\mathrm{t}(65)$ $=0.64, \mathrm{~ns})$.

\section{Verbal and Visual Memory Tests}

The Korean version of the California Verbal Learning Test (K-CVLT) was administered to measure verbal memory [39]. The K-CVLT consists of five free-recall trials of List A, a free-recall trial of List B, and free-recall and cued-recall trials of List A (short-term free recall and cued recall of List A). Then, after a 20-minute delay, free-recall, cued-recall, and recognition tests of List A (long-term free-recall, cued-recall and recognition tests of List A) are administered. The total number of responses to the five trials for List A, the numbers of short-term and long-term free-recall responses for List A, and the recognition percentage of List A were included in the analysis.

The Rey-Osterrieth Complex Figure Test (RCFT) was administered to evaluate nonverbal memory [40]. The RCFT involves three conditions; copying, immediate recall and delayed recall, which are followed by recognition trials. Response times and accuracy were scored for each condition based on the system developed by Meyers and Meyers [41]. The Korean-Wechsler Adult Intelligence Scale (K-WAIS; [42]) was administered to measure IQ.

\subsection{Clinical Assessment}

The Schizotypal Personality Questionnaire (SPQ) is a 74-item self-administered questionnaire with a "yes/no" 
response format [36]; the Korean version of the SPQ [43] was used in the present study. All items answered "yes" are scored as 1 and higher scores indicate greater schizotypy. The SPQ consists of nine subscales that load onto three factors: cognitive-perceptual (ideas of reference, odd beliefs/magical thinking, unusual perceptual experiences, and suspiciousness/paranoid ideations), interpersonal experiences (social anxiety, no close friends, constricted affect, and suspiciousness), and disorganization (eccentric/odd behavior and odd speech). The cognitive-perceptual, interpersonal experiences, and disorganization factors measured by the SPQ reflect the positive, negative, and disorganized symptoms of schizophrenia, respectively [44] [45].

\subsection{Statistical Analysis}

The time widows of N100, P200, N250 and P300 were determined following a visual inspection of the grandaveraged and individual ERP waveforms (see Figure 1). N100 was defined as the most negative peak observed between 100 and 160 ms after stimulus-onset and P200 was defined as the most positive peak observed between 180 and 240 ms after stimulus-onset. N250 was defined as the most negative peak observed between 250 and 350 ms after stimulus-onset and P300 was defined as the most positive peak observed between 350 and $450 \mathrm{~ms}$ after stimulus-onset. All four peaks were observed at Fz and Cz while only N100 and P300 were observed at Pz.

The amplitudes and latencies of the peaks were analyzed with a mixed-design repeated measures analysis of variance ANOVA using electrode site as a within-subject factor $(\mathrm{Fz}, \mathrm{Cz}$, and $\mathrm{Pz}$ for the analysis of N100 and P300 and Fz and Cz for the analysis of P200 and N250) and group (schizotypal-trait and control groups) as a between-subject factor. Greenhouse-Geisser corrections for violations of sphericity were used when appropriate, and the corrected $\mathrm{p}$ values are reported. Variables showing significant main effects were further analyzed by post hoc comparisons with a one-way ANOVA. Performances on the K-CVLT and RCFT were analyzed with an ANOVA and the associations among ERP peak amplitudes, performances on the K-CVLT and RCFT measures, and the three factors of the SPQ were examined using Pearson product-moment correlations. The demo-

(a)
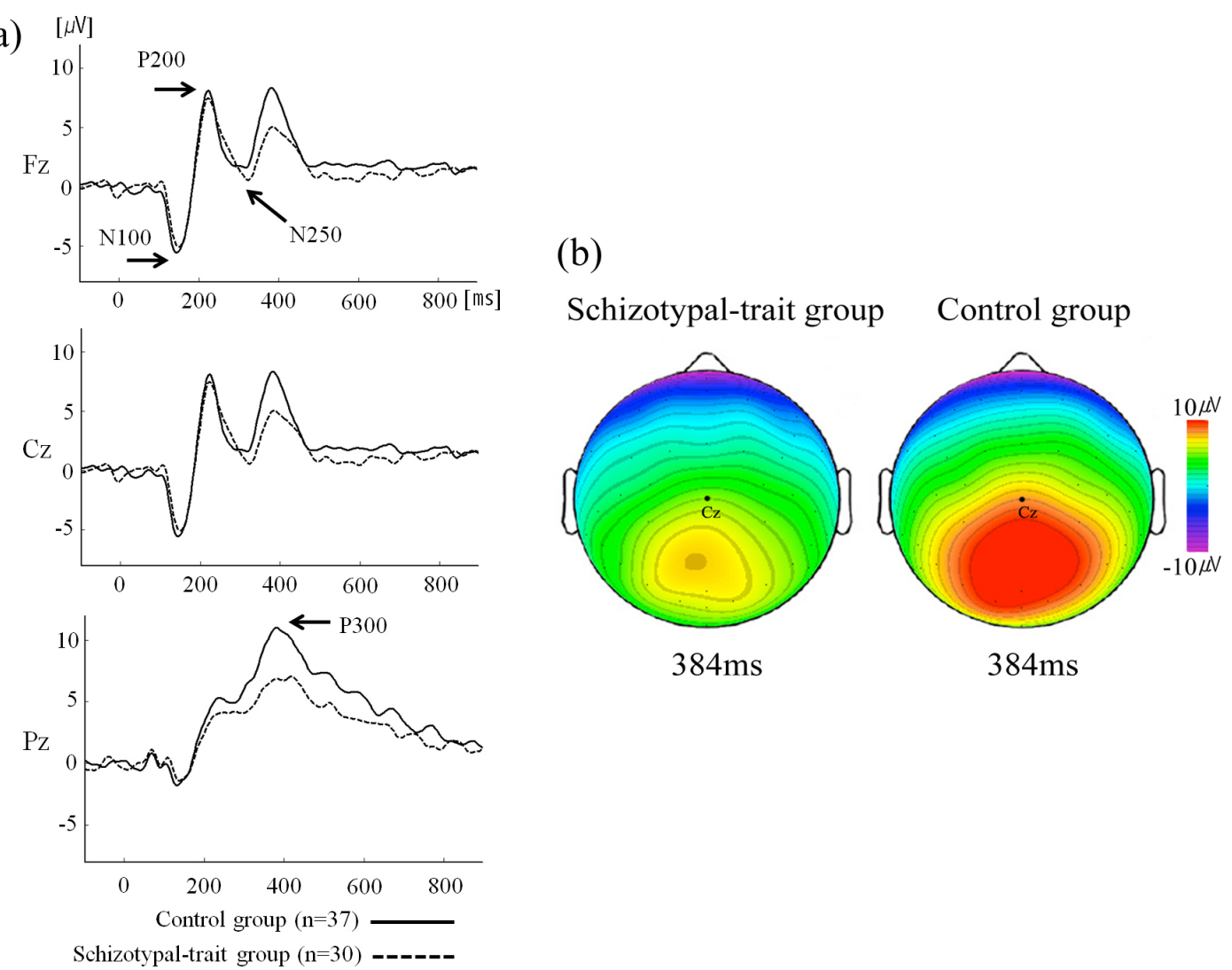

$384 \mathrm{~ms}$

Figure 1. (a) Grand average event-related potentials elicited by target stimuli in control and schizotypal-trait groups; (b) Topographical distributions of P300 elicited by target stimuli in control and schizotypal-trait groups. 
graphic characteristics of the participants were analyzed by means of independent $t$-tests.

\section{Results}

\subsection{Demographic Characteristics}

The demographic characteristics and SPQ scores of the schizotypal-trait and control groups are described in Table 1 . The two groups did not differ in terms of mean age $(\mathrm{t}(65)=0.29$, ns), years of education $(\mathrm{t}(65)=0.57$, ns), or total IQ $(\mathrm{t}(65)=-0.39$, ns). However, the SPQ scores of the two groups differed significantly $(\mathrm{t}(65)=-24.74$, $\mathrm{p}<0.001$ ) such that the schizotypal-trait group obtained higher scores on the SPQ compared to the control group.

\subsection{Electrophysiological Measurement}

Figure 1(a) displays the grand-averages of the ERPs elicited by target stimuli at Fz, Cz, and Pzand depicts the topographical distribution of electrical activity measured at all 64 sites at the time of the generation of P300 Figure 1(b).

\subsubsection{N100}

Analysis of the amplitude of N100 revealed a main effect of electrode site $(F(2,130)=89.79, p<0.001)$ with the largest amplitude at $\mathrm{Fz}(-7.06 \mu \mathrm{V})$, followed by $\mathrm{Cz}(-6.22 \mu \mathrm{V})$, and finally $\mathrm{Pz}(-3.11 \mu \mathrm{V})$. The schizotypal-trait and control groups did not differ in terms of $\mathrm{N} 100$ amplitude $(\mathrm{F}(1,65)=0.30$, ns) and there were no significant main effects of group or electrode site or interaction effects of group by electrode site in terms of N100 latency.

\subsubsection{P200}

A main effect of electrode site was observed for P200 $(F(1,65)=75.87, \mathrm{p}<0.001)$ such that the amplitude elicited at $\mathrm{Cz}(8.87 \mu \mathrm{V})$ was significantly larger than the amplitude elicited at $\mathrm{Fz}(5.95 \mu \mathrm{V})$. However, the two groups did not differ in terms of P200 amplitude $(F(1,65)=0.66$, ns), and there were no significant main effects of group or electrode site or interaction effects of group by electrode site in terms of P200 latency.

\subsubsection{N250}

A main effect of electrode site was observed for N250 $(F(1,65)=73.87, p<0.001)$ such that the amplitude elicited at $\mathrm{Fz}(-4.91 \mu \mathrm{V})$ was significantly larger than the amplitude elicited at $\mathrm{Cz}(0.45 \mu \mathrm{V})$. However, the two groups did not differ in terms of the amplitude of $\mathrm{N} 250(\mathrm{~F}(1,65)=0.03$, ns), and there were no significant main effects of group or electrode site or interaction effects of group by electrode site in terms of N250 latency.

\subsubsection{P300}

There were main effects of group $(F(1,65)=28.52, p<0.001)$ and electrode site $(F(2,130)=128.87, p<0.001)$

Table 1. Demographic characteristics of control and schizotypal-trait groups.

\begin{tabular}{|c|c|c|c|c|c|}
\hline & \multicolumn{2}{|c|}{ Control group $(\mathrm{n}=37)$} & \multicolumn{2}{|c|}{ Schizotypal-trait group $(n=30)$} & \multirow{2}{*}{$t$} \\
\hline & Mean & SD & Mean & $\mathrm{SD}$ & \\
\hline Age (years) & 20.73 & 1.81 & 20.60 & 1.87 & 0.29 \\
\hline Education (years) & 14.27 & 0.90 & 14.13 & 1.07 & 0.57 \\
\hline IQ & 109.43 & 6.16 & 110.03 & 6.39 & -0.39 \\
\hline SPQ (total score) & 17.81 & 1.87 & 40.03 & 5.06 & $-24.74^{* * *}$ \\
\hline Cognitive-perceptual & 7.78 & 2.58 & 15.90 & 4.07 & -9.92 \\
\hline Interpersonal & 8.19 & 3.51 & 18.03 & 5.22 & -9.20 \\
\hline Disorganization & 3.38 & 2.10 & 9.20 & 3.20 & -8.95 \\
\hline
\end{tabular}

SPQ: Schizotypal Personality Questionnaire; SD: Standard deviation; ${ }^{* * *} \mathrm{p}<0.001$. 
for P300 amplitude. The schizotypal-trait group exhibited significantly smaller P300 amplitudes (5.56 $\mu \mathrm{V})$ than the control group $(9.05 \mu \mathrm{V})$ at $\mathrm{Fz}(\mathrm{F}(1,65)=6.76, \mathrm{p}<0.05)$, $\mathrm{Cz}(\mathrm{F}(1,65)=16.91, \mathrm{p}<0.001)$, and $\mathrm{Pz}(\mathrm{F}(1,65)=$ 6.94, $\mathrm{p}<0.001)$. The largest $\mathrm{P} 300$ amplitude was observed at $\mathrm{Pz}(10.41 \mu \mathrm{V})$, followed by $\mathrm{Cz}(7.88 \mu \mathrm{V})$, and finally Fz $(3.64 \mu \mathrm{V})$. There were no significant main effects of group $(\mathrm{F}(1,65)=0.05$, ns)or electrode site $(F(2,130)=1.03$, ns $)$ or interaction effects of group by electrode site $(F(2,130)=0.07$, ns $)$ in terms of P300 latency. The mean amplitudes and latencies for all four ERP peaks in the schizotypal-trait and control groups are presented in Table 2.

\subsection{Performance on the Verbal and Visual Memory Tests}

Table 3 shows the results of the K-CVLT and RCFT measures for the schizotypal-trait and control groups. Regarding the K-CVLT, the two groups did not differ in terms of the total number of responses during the five tri-

Table 2. The mean amplitudes $(\mu \mathrm{V})$ and latencies (ms) in control and schizotypal-trait groups.

\begin{tabular}{|c|c|c|c|c|c|}
\hline & \multirow{2}{*}{ Channel } & \multicolumn{2}{|c|}{ Amplitude $(\mu \mathrm{V})$} & \multicolumn{2}{|c|}{ Latency (ms) } \\
\hline & & $\begin{array}{l}\text { Control group } \\
\quad(\mathrm{n}=37)\end{array}$ & $\begin{array}{l}\text { Schizotypal-trait group } \\
\qquad(\mathrm{n}=30)\end{array}$ & $\begin{array}{l}\text { Control group } \\
\quad(\mathrm{n}=37)\end{array}$ & $\begin{array}{l}\text { Schizotypal-trait group } \\
\qquad(\mathrm{n}=30)\end{array}$ \\
\hline \multirow{3}{*}{ N100 } & $\mathrm{Fz}$ & $-7.22(2.85)$ & $-6.90(2.92)$ & $143.46(9.71)$ & $145.20(10.19)$ \\
\hline & $\mathrm{Cz}$ & $-6.41(2.22)$ & $-6.03(3.14)$ & 143.89 (11.49) & 146.67 (11.13) \\
\hline & $\mathrm{Pz}$ & $-3.17(1.89)$ & $-3.05(1.81)$ & 138.92 (11.91) & $140.53(11.53)$ \\
\hline \multirow{2}{*}{ P200 } & $\mathrm{Fz}$ & $6.35(4.02)$ & $5.54(3.60)$ & 221.41 (15.89) & 221.87 (15.10) \\
\hline & $\mathrm{Cz}$ & $9.22(4.65)$ & $8.51(3.81)$ & 222.70 (13.57) & 224.13 (13.47) \\
\hline \multirow{2}{*}{ N250 } & $\mathrm{Fz}$ & $-5.00(2.04)$ & $-4.81(2.04)$ & 306.27 (25.36) & 310.93 (21.58) \\
\hline & $\mathrm{Cz}$ & $-0.68(1.97)$ & $0.22(1.72)$ & 305.59 (21.43) & 312.27 (15.28) \\
\hline \multirow{3}{*}{ P300 } & $\mathrm{Fz}$ & $4.87(3.76)$ & $2.40(4.07)$ & 383.14 (19.05) & 384.93 (20.67) \\
\hline & $\mathrm{Cz}$ & $9.56(3.00)$ & 6.19 (3.70) & 385.62 (17.22) & $386.70(20.50)$ \\
\hline & $\mathrm{Pz}$ & $12.71(2.94)$ & $8.10(2.20)$ & 386.05 (19.63) & 386.53 (21.44) \\
\hline
\end{tabular}

() Standard deviation.

Table 3. Verbal and visual memory performances of control and schizotypal-trait groups.

\begin{tabular}{ccccc}
\hline & \multicolumn{2}{c}{ Control group $(\mathrm{n}=37)$} & \multicolumn{2}{c}{ Schizotypal-trait group $(\mathrm{n}=30)$} \\
\cline { 2 - 4 } & Mean & SD & Mean \\
\hline K-CVLT & & & \\
List A trails 1 - 5 & 68.86 & 6.27 & 69.80 & 5.61 \\
List A short-term free recall & 14.86 & 1.55 & 14.90 & 1.09 \\
List A long-term free recall & 14.97 & 1.28 & 14.50 & 0.78 \\
Recognition rate (\%) & 99.68 & 0.75 & 99.20 & 1.42 \\
RCFT (accuracy) & & & 32.77 & 6.12 \\
Copy & 33.05 & 2.20 & 21.08 & 5.72 \\
Immediate recall & 21.65 & 5.16 & 21.52 & 2.02 \\
Delayed recall & 22.22 & 5.41 & 20.73 & \\
Recognition & 20.59 & 2.29 & & \\
\hline
\end{tabular}

K-CVLT: Korean version of California Verbal Learning Test; RCFT: Rey-Osterrieth Complex Figure Test; SD: Standard deviation. 
als using List A, the number of short-term and long-term free-recall responses for List A, or the recognition percentage for List A. Additionally, the two groups did not differ with respect to reaction time or accuracy on the copy, immediate recall, delayed recall, and recognition tests of the RCFT. Therefore, the associations between P300 amplitude and performances on the verbal/nonverbal memory tests were not analyzed further.

\subsection{Correlations between the Amplitude of P300 and Scores on the SPQ}

There were significant negative correlations between the cognitive-perceptual score on the SPQ and the P300 amplitudes measured at $\mathrm{Cz}(\mathrm{r} 65=-4.0, \mathrm{p}<0.05)$ and $\mathrm{Pz}(\mathrm{r} 65=-0.43, \mathrm{p}<0.05)$ in the schizotypal-trait group but not the control group.

\section{Discussion}

The present study investigated whether college students with psychometrically defined schizotypal-traits exhibited reduced P300 amplitudes and, if so, the manner in which the reduced amplitudes were related to schizophrenic symptoms and performance on memory tests. Compared to the control group, the schizotypal-trait group exhibited significantly smaller P300 amplitudes, which is consistent with previous studies investigating schizophrenia patients [12] [46], SPD patients [33], and college students with schizotypal-traits [34] [35].

The characteristics of the P300 component are determined by a wide range of psychological and neuroanatomical factors [47]. The most important psychological factors that influence P300 are motivation and sustained attention. Instructions that are designed to motivate participants increase P300 amplitudes [48], and there is a negative correlation between performance on attentional tests and P300 amplitudes in healthy controls [49]. Moreover, children with attention deficit/hyperactivity disorder exhibit reduced P300 amplitudes [50]. Attentional impairment and a lack of motivation, which are frequently present in patients with schizophrenia, may contribute to reductions of the P300 amplitude [47]. However, in the present study, the reduced P300 amplitudes that were observed in individuals with schizotypal-traits do not seem to be the result of lowered motivation or attention difficulties. The oddball task administered in the present study required the participants to count the number of targets in series of stimuli and successful performance on this task demands the maintenance of one's attention. The schizotypal-trait and control groups did not differ in terms of performance on the oddball task. Additionally, the amplitudes and latencies of N100, an index of selective attention [22], did not differ between the two groups. These findings indicate that both groups were cooperative and attentive to the task.

The medial temporal lobe, parietal lobe, and prefrontal cortex are known as generators of the P300 and, thus, the reduced P300 amplitudes observed in patients with schizophrenia are likely related to structural abnormalities in these areas. For example, patients with schizophrenia exhibit reductions in gray matter volume in the frontal and temporoparietal areas [51] and an association between reduced P300 amplitudes and reduced volumes of the left superior temporal gyrus [52] and parietal areas [53] has been reported. Negative correlations have also been observed between P300 amplitudes and performance on verbal memory tests [12] [16]. However, in the present study, the schizotypal-trait and control groups did not differ in terms of performance on the verbal and nonverbal memory tests. Discrepancies among the findings of studies may be related to the characteristics of the participants. For example, Chang et al. [18] did not find a significant correlation between P300 amplitudes and verbal memory performance in first-episode drug-naive patients with schizophrenia, and a functional magnetic resonance (fRMI) study reported that reductions in the volume of the superior temporal gyrus worsen as schizophrenia progresses [54].

The present study identified a significant negative correlation between P300 amplitudes and the cognitiveperceptual score on the SPQ. In other words, as the symptoms within the cognitive-perceptual factor (ideas of reference, odd beliefs/magical thinking, unusual perceptual experiences, and suspiciousness/paranoid ideations) became more severe, there was a greater reduction of P300 amplitudes. This finding is consistent with previous report of a significant negative correlation between P300 amplitudes and positive symptoms in patients with schizophrenia [20] [21]. Although the relationship between P300 amplitudes and the positive symptoms of schizophrenia is not yet fully understood, these features seem to interfere with the allocation of attention that is required for P300 generation [5] [21]. However, previous studies investigating the relationship between P300 amplitudes and schizophrenic symptoms have yielded inconsistent results. Some studies report a negative association between P300 amplitudes and negative symptoms [19], while others suggest that P300 amplitudes increase as schizophrenic symptoms are relieved [21] [55], and still others report that the alleviation of symptoms 
does not influence P300 amplitudes [56]. Therefore, further study is needed to better understand the relationships between P300 amplitudes and schizophrenic symptoms.

The schizotypal-trait and control groups in the present study did not differ in terms of amplitude or latency for the N100, P200, and N250 peaks. N100, P200, and N250 reflect selective attention [22], sensory encoding [57], and the classification/categorization of stimuli [58], respectively. Therefore, the present findings indicate that individuals with schizotypal-traits maintain the cognitive abilities required for the early stages of information processing.

The present study has several limitations that should be considered in future studies. First, the present study investigated the relationship between P300 amplitudes and performance on verbal/nonverbal memory tasks. Because various cortical areas, including the prefrontal cortex, are considered to be P300 generators, an investigation of the relationships between P300 amplitudes and various cognitive functions would provide more comprehensive information regarding the relationships among these factors. Second, this study analyzed only the amplitudes and latencies of ERP peaks. Future studies of the cortical generators of P300 using source localization or the functional connectivity networks of P300 [59] would provide valuable information regarding the structural/functional abnormalities associated with reduced P300 amplitudes. Finally, the inclusion of only a small number of participants limits the generalizability of the findings.

\section{Conclusion}

In summary, individuals with schizotypal-traits exhibited significantly smaller P300 amplitudes relative to controls, and the P300 amplitudes measured at $\mathrm{Cz}$ and $\mathrm{Pz}$ were negatively correlated with the cognitive-perceptual score on the SPQ. These findings indicate that reduced P300 amplitudes could serve as a biological marker for, or risk factor of schizophrenia.

\section{Acknowledgements}

This work was supported by the Sungshin Women’s University Research Grant of 2013.

\section{References}

[1] Hillyard, S.A. and Kutas, M. (1983) Electrophysiology of Cognitive Processing. American Review of Psychology, 34, 33-61. http://dx.doi.org/10.1146/annurev.ps.34.020183.000341

[2] Luck, S.L. (2005) An Introduction to the Event-Related Potential Technique. Massachusetts Institute of Technology, Cambridge, 21-25.

[3] Donchin, E. and Coles, M.G.H. (1988) Is the P300 Component a Manifestation of Context Updating? Behavioral Brain Science, 11, 357-374. http://dx.doi.org/10.1017/S0140525X00058027

[4] Sutton, S., Braren, M., Zubin, J. and John, E.R. (1965) Evoked-Potential Correlates of Stimulus Uncertainty. Science, 150, 1187-1188. http://dx.doi.org/10.1126/science.150.3700.1187

[5] Kok, A. (2001) On the Utility of P3 Amplitude as a Measure of Processing Capacity. Psychophysiology, 38, 557-577. http://dx.doi.org/10.1017/S0048577201990559

[6] Bramon, E., Rabe-Hesketh, S., Sham, P., Murray, R.M. and Frangou, S. (2004) Meta-Analysis of the P300 and P50 Waveforms in Schizophrenia. Schizophrenia Research, 70, 315-329. http://dx.doi.org/10.1016/j.schres.2004.01.004

[7] Jeon, Y. and Polich, J. (2003) Meta-Analysis of P300 and Schizophrenia: Patients, Paradigms, and Practical Implications. Psychophysiology, 40, 684-701. http://dx.doi.org/10.1111/1469-8986.00070

[8] Levit, R.A., Sutton, S. and Zubin, J. (1973) Evoked Potential Correlates of Information Processing in Psychiatric Patients. Psychological Medicine, 3, 487-494. http://dx.doi.org/10.1017/S0033291700054295

[9] van der Stelt, O., Lieberman, J.A. and Belger, A. (2005) Auditory P300 in High-Risk, Recent-Onset and Chronic Schizophrenia. Schizophrenia Research, 77, 309-320. http://dx.doi.org/10.1016/j.schres.2005.04.024

[10] Kim, M.S., Cho, S.S., Park, S.J., Kim, Y.S., Kim, J.J. and Kwon, J.S. (2001) The Correlational Study of Event-Related Potential (ERP) and the Performance of Neuropsychological Tests in Schizophrenic Patients. Korean Journal of Clinical Psychology, 20, 359-373.

[11] Ford, J.M., Roth, W.T. and Pfefferbaum, A. (1992) P3 and Schizophrenia. Annals of the New York Academy of Sciences, 658, 146-162. http://dx.doi.org/10.1111/j.1749-6632.1992.tb22843.x

[12] Kim, M.S., Kang, S.S., Youn, T., Kang, D.H., Kim, J.J. and Kwon, J.S. (2003) Neuropsychological Correlate of P300 
Abnormalities in Patients with Schizophrenia and Obsessive-Compulsive Disorder. Psychiatry Research: Neuroimaging, 123, 109-123. http://dx.doi.org/10.1016/S0925-4927(03)00045-3

[13] Demiralp, T., Ucok, A., Devrim, M., Isoglu-Alkac, U., Tecer, A. and Polich, J. (2002) N2 and P3 Components of Event-Related Potential in First-Episode Schizophrenic Patients: Scalp Topography, Medication and Latency Effects. Psychiatry Research, 111, 167-179. http://dx.doi.org/10.1016/S0165-1781(02)00133-6

[14] Umbricht, D.S.G., Bates, J.A., Lieberman, J.A., Kane, J.M. and Javitt, D.C. (2006) Electrophysiological Indices of Automatic and Controlled Auditory Information Processing in First-Episode, Recent-Onset and Chronic Schizophrenia. Biological Psychiatry, 59, 762-772. http://dx.doi.org/10.1016/j.biopsych.2005.08.030

[15] Turetsky, B.I., Cannon, T.D. and Gur, R.E. (2000) P300 Subcomponent Abnormalities in Schizophrenia III: Deficits in Unaffected Siblings of Schizophrenic Probands. Biological Psychiatry, 47, 380-390. http://dx.doi.org/10.1016/S0006-3223(99)00290-5

[16] Nagasawa, T., Kamiya, T., Kawasaki, Y., Higashima, M., Urata, K., Sakai, N. and Koshino, Y. (1999) The Relationship between Auditory ERP and Neuropsychological Assessments in Schizophrenia. International Journal of Psychophysiology, 34, 267-274. http://dx.doi.org/10.1016/S0167-8760(99)00083-5

[17] van der Stelt, O. and Belger, A. (2007) Application of Electroencephalography to the Study of Cognitive and Brain Functions in Schizophrenia. Schizophrenia Bulletin, 33, 955-970. http://dx.doi.org/10.1093/schbul/sbm016

[18] Chang, W.H., Chen, K.C., Yang, Y.K., Chen, P.S., Lu, R.B., Yeh, T.L., Wang, C.S.M. and Lee, I.H. (2014) Association between Auditory P300, Psychopathology and Memory Function in Drug-Naive Schizophrenia. Kaohsiung Journal of Medical Science, 30, 133-138. http://dx.doi.org/10.1016/j.kjms.2013.10.003

[19] Liu, Z., Tam, W.C.C., Xue, Z., Yao, S. and Wu, D. (2004) Positive and Negative Symptom Profile Schizophrenia and Abnormalities in the P300 Component of the Event-Related Potential: A Longitudinal Controlled Study. Psychiatry Research: Neuroimaging, 132, 131-139. http://dx.doi.org/10.1016/j.pscychresns.2004.03.003

[20] Egan, M.F., Duncan, C.C., Suddath, R.L., Kirch, D.G., Mirsky, A.F. and Wyatt, R.J. (1994) Event-Related Potential Abnormalities Correlate with Structural Brain Alterations and Clinical Features in Patients with Chronic Schizophrenia. Schizophrenia Research, 11, 259-271. http://dx.doi.org/10.1016/0920-9964(94)90020-5

[21] Higashima, M., Nagasawa, T., Kawasaki, Y., Oka, T., Sakai, N., Tsukada, T. and Koshino, Y. (2002) Auditory P300 Amplitude as a State Marker for Positive Symptoms in Schizophrenia: Cross-Sectional and Retrospective Longitudinal Studies. Schizophrenia Research, 59, 147-157. http://dx.doi.org/10.1016/S0920-9964(01)00397-8

[22] Shelley, A.M., Silipo, G. and Javitt, D.C. (1999) Diminished Responsiveness of ERPs in Schizophrenic Subjects to Changes in Auditory Stimulation Parameter: Implications for Theories of Cortical Dysfunction. Schizophrenia Research, 37, 65-79. http://dx.doi.org/10.1016/S0920-9964(98)00138-8

[23] Javitt, D.C., Doneshka, P., Grochowski, S. and Ritter, W. (1995) Impaired Mismatch Negativity Generation Reflects Widespread Dysfunction of Working Memory in Schizophrenia. Archives of General Psychiatry, 52, 550-558. http://dx.doi.org/10.1001/archpsyc.1995.03950190032005

[24] Cornblatt, B., Lencz, T. and Obuchowski, M. (2002) The Schizophrenia Prodrome: Treatment and High-Risk Perspectives. Schizophrenia Research, 54, 177-186. http://dx.doi.org/10.1016/S0920-9964(01)00365-6

[25] Kim, K.R., Park, J.Y., Song, D.H., Koo, H.K. and An, S.K. (2011) Neurocognitive Performance in Subjects at Ultrahigh Risk for Schizophrenia: A Comparison with First-Episode Schizophrenia. Comprehensive Psychiatry, 52, 33-40. http://dx.doi.org/10.1016/j.comppsych.2010.04.010

[26] Lawrie, S.M., Whalley, H.C., Abukmeil, S.S., Kestelman, J.N., Donnelly, L., Miller, P., Best, J.J.K., Owens, D.G.C. and Johnstone, E.C. (2001) Brain Structure, Genetic Liability and Psychotic Symptoms in Subjects at High Risk of Developing Schizophrenia. Biological Psychiatry, 49, 811-823. http://dx.doi.org/10.1016/S0006-3223(00)01117-3

[27] Siever, L.J. and Davis, K.L. (2004) The Pathophysiology of Schizophrenia Disorders: Perspectives from the Spectrum. American Journal of Psychiatry, 161, 398-413. http://dx.doi.org/10.1176/appi.ajp.161.3.398

[28] Yung, A.R., Phillips, L.J., Yuen, H.P., Francey, S.M., McFarlane, C.A., Hallgren, M. and McGorry, P.D. (2003) Psychosis Prediction: 12-Month Follow up of a High-Risk ("Prodromal”) Group. Schizophrenia Research, 60, 21-32. http://dx.doi.org/10.1016/S0920-9964(02)00167-6

[29] Lin, H.F., Liu, Y.L., Liu, C.M., Hung, S.I., Hwu, H.G. and Chen, W.J. (2005) Neuregulin I Gene and Variations in Perceptual Aberration of Schizotypal Personality in Adolescents. Psychological Medicine, 35, 1589-1598. http://dx.doi.org/10.1017/S0033291705005957

[30] Moorhead, T.W.J., Stanfield, A., Spencer, M., Hall, J., McIntosh, A., Qwnes, D.C., Lawrie, S. and Johnstone, E. (2009) Progressive Temporal Gray Matter Loss in Adolescents with Schizotypal Traits and Mild Intellectual Impairment. Psychiatry Research: Neuroimaging, 174, 105-109. http://dx.doi.org/10.1016/j.pscychresns.2009.04.003

[31] Kim, M.S., Oh, S.H., Hong, M.H. and Choi, D.B. (2011) Neuropsychologic Profile of College Students with Schizo- 
typal Traits. Comprehensive Psychiatry, 52, 511-516. http://dx.doi.org/10.1016/j.comppsych.2010.10.010

[32] Noguchi, H., Hori, H. and Kunugi, H. (2008) Schizotypal Traits and Cognitive Function in Healthy Adults. Psychiatry Research, 161, 162-169. http://dx.doi.org/10.1016/j.psychres.2007.07.023

[33] Salisbury, D.F., Voglmaier, M.M., Seidman, L.J. and McCarley, R.W. (1996) Topographic Abnormalities of P3 in Schizotypal Personality Disorder. Biological Psychiatry, 40, 165-172. http://dx.doi.org/10.1016/0006-3223(95)00373-8

[34] Gassab, L., Mechri, A., Dogui, M., Gaha, L., d’Amato, T., Dalery, J. and Saoud, M. (2006) Abnormalities of Auditory Event-Related Potentials in Student with High Scores on the Schizotypal Personality Questionnaire. Psychiatry Research, 144, 117-122. http://dx.doi.org/10.1016/j.psychres.2004.09.010

[35] Mannan, R., Hiramatsu, K.I., Hokama, H. and Ohta, H. (2001) Abnormalities of Auditory Event-Related Potentials in Students with Schizotypal Personality Disorder. Psychiatry and Clinical Neurosciences, 55, 451-457. http://dx.doi.org/10.1046/j.1440-1819.2001.00889.x

[36] Raine, A. (1991) The SPQ: A Scale for the Assessment of Schizotypal Personality Based on DSM-III-R Criteria. Schizophrenia Bulletin, 17, 555-564. http://dx.doi.org/10.1093/schbul/17.4.555

[37] First, M.B., Spitzer, R.L., Gibbson, M. and Williams, J.B.W. (1996) Structured Clinical Interview for DSM-IV Axis I Disorder. New York State Psychiatric Institute, New York.

[38] Tucker, D.M. (1993) Spatial Sampling of Head Electric Fields: The Geodesic Sensor Net. Electroencephalography and Clinical Neurophysiology, 87, 154-163. http://dx.doi.org/10.1016/0013-4694(93)90121-B

[39] Kim, J.K. and Kang, Y.W. (1999) Korean-California Verbal Learning Test (K-CVLT). Seoul.

[40] Shorr, J.S., Delis, D.C. and Massman, P.J. (1992) Memory for the Rey-Osterrieth Figure: Perceptual Clustering, Encoding and Storage. Neuropsychologia, 6, 43-50. http://dx.doi.org/10.1037/0894-4105.6.1.43

[41] Meyers, J.E. and Meyers, K.R. (1995) Rey Complex Figure Test and Recognition Trial: Professional Manual. Psychological Assessment Resources, Odessa.

[42] Yeom, T.H., Park, Y.S., Oh, K.J., Kim, J.G. and Lee, Y.H. (1992) Korean Wechsler Adult Intelligence Scale (K-WAIS) Manual. Handbook Guidence, Seoul.

[43] Moon, H.O., Yang, I.H., Lee, H.P., Kim, M.E. and Ham, W. (1997) The Preliminary Study on the Validation of Schizotypal Personality Questionnaire-Korean Version. Journal of Korean Neuropsychiatry Association, 36, 329-343.

[44] Matheson, S. and Langdon, R. (2008) Schizotypal Traits Impact upon Executive Working Memory and Aspects of IQ. Psychiatry Research, 159, 207-214. http://dx.doi.org/10.1016/j.psychres.2007.04.006

[45] Hahn, O.S., Ahn, J.H., Song, S.H., Cho, M.J., Kim, J.K., Bae, J.N., et al. (2000) Development of Korean Version of Structured Clinical Interview Schedule for DSM-IV Axis I Disorder: Interrater Reliability. Journal of Korean Neuropsychiatry Association, 39, 362-372.

[46] Jeon, Y. and Polich, J. (2001) P300 Asymmetry in Schizophrenia: A Meta-Analysis. Psychiatry Research, 104, 61-74. http://dx.doi.org/10.1016/S0165-1781(01)00297-9

[47] Ford, J.M. (1999) Schizophrenia: The Broken P300 and Beyond. Psychophysiology, 36, 667-682. http://dx.doi.org/10.1111/1469-8986.3660667

[48] Carrillo-de-la-Pena, M.T. and Cadaveira, F. (2000) The Effect of Motivational Instructions on P300 Amplitude. Clinical Neurophysiology, 30, 232-239. http://dx.doi.org/10.1016/S0987-7053(00)00220-3

[49] Portin, R., Kovala, T., Polo-Kantola, P., Revonsuo, A., Muller, K. and Matikainen, E. (2000) Does P3 Reflect Attentional or Memory Performances, or Cognition More Generally? Scandinavian Journal of Psychology, 41, 31-40. http://dx.doi.org/10.1111/1467-9450.00168

[50] Puente, A., Ysnuza, A., Pamplona, M., Silva-Rojas, A. and Lara, C. (2002) Short Latency and Long Latency Auditory Evoked Responses in Children with Attention Deficit Disorder. International Journal of Pediatric Otorhinolaryngology, 62, 45-51. http://dx.doi.org/10.1016/S0165-5876(01)00596-1

[51] McCarley, R.W., Wible, C.G., Frumin, M., Hirayasu, Y., Levitt, J.J., Fischer, I.A. and Shenton, M.E. (1999) MRI Anatomy of Schizophrenia. Biological Psychiatry, 45, 1099-1119. http://dx.doi.org/10.1016/S0006-3223(99)00018-9

[52] O’Donnell, B.F., Shenton, M.E., McCarley, R.W., Faux, S.F., Smith, R.S., Salisbury, D.F., et al. (1993) The Auditory N2 Component in Schizophrenia: Relationship to MRI Temporal Lobe Gray Matter and to Other ERP Abnormalities. Biological Psychiatry, 34, 26-40. http://dx.doi.org/10.1016/0006-3223(93)90253-A

[53] Ford, J.M., White, P., Lim, K.O. and Pfefferbaum, A. (1994) Schizophrenics Have Fewer and Smaller P300s: A Single-Trial Analysis. Biological Psychiatry, 35, 96-103. http://dx.doi.org/10.1016/0006-3223(94)91198-3

[54] Kasai, K., Shenton, M.E., Salisbury, D.F., Hirayasu, Y., Lee, C.U., Ciszewski, A.A., et al. (2003) Progressive Decrease of Left Superior Temporal Gyrus Gray Matter Volume in Patients with First-Episode Schizophrenia. American Journal of Psychiatry, 160, 156-164. http://dx.doi.org/10.1176/appi.ajp.160.1.156 
[55] Mathalon, D.H., Ford, J.M. and Pfefferbaum, A. (2000) Trait and State Aspects of P300 Amplitude Reduction in Schizophrenia: A Retrospective Longitudinal Study. Biological Psychiatry, 47, 434-449.

http://dx.doi.org/10.1016/S0006-3223(99)00277-2

[56] Turetsky, B., Colbath, E.A. and Gur, R.E. (1998) P300 Subcomponent Abnormalities in Schizophrenia: Longitudinal Stability and Relationship to Symptom Change. Biological Psychiatry, 43, 31-39. http://dx.doi.org/10.1016/S0006-3223(97)00261-8

[57] Dunn, B.R., Dunn, D.A. and Languis, M. (1998) The Reflection of ERP Components to Complex Memory Processing. Brain and Cognition, 36, 355-376. http://dx.doi.org/10.1006/brcg.1998.0998

[58] Renaullt, B., Ragot, R., Lesevre, N. and Remond, A. (1982) Onset and Offset of Brain Events as Indices of Mental Chronometry. Science, 215, 1413-1415. http://dx.doi.org/10.1126/science.7063853

[59] Shim, M., Kim, D.W., Lee, S.H. and Im, C.H. (2014) Disruptions in Small-World Cortical Functional Connectivity Network during an Auditory Oddball Paradigm Task in Patients with Schizophrenia. Schizophrenia Research, 156, 197-203. http://dx.doi.org/10.1016/j.schres.2014.04.012 
Scientific Research Publishing (SCIRP) is one of the largest Open Access journal publishers. It is currently publishing more than 200 open access, online, peer-reviewed journals covering a wide range of academic disciplines. SCIRP serves the worldwide academic communities and contributes to the progress and application of science with its publication.

Other selected journals from SCIRP are listed as below. Submit your manuscript to us via either submit@scirp.org or Online Submission Portal.
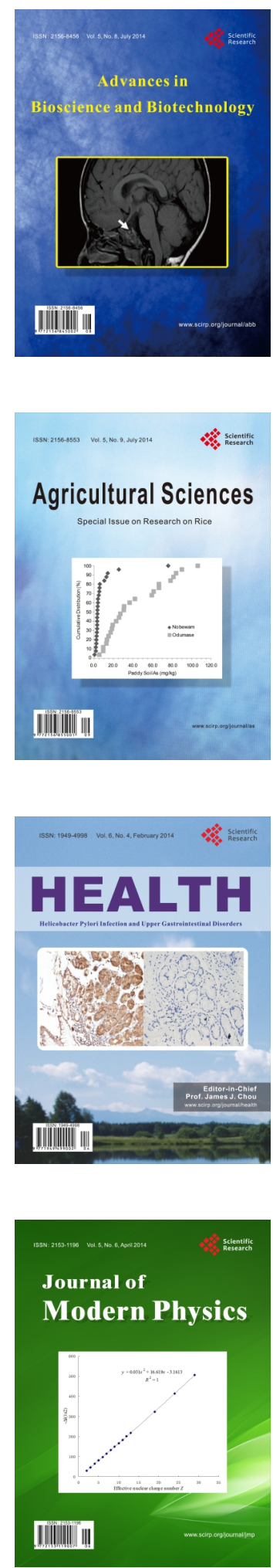
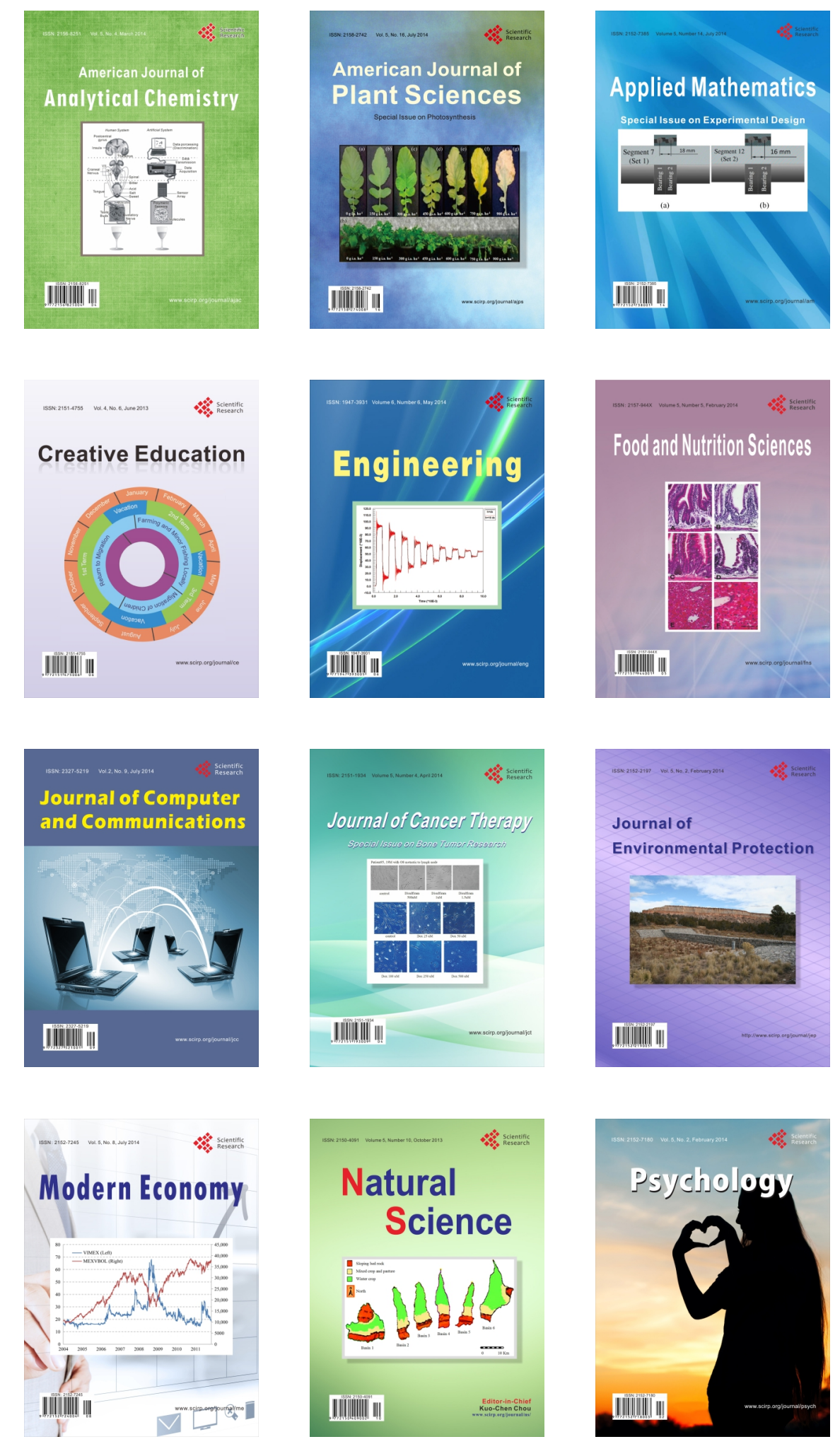